\title{
Once-yearly device takes on daily and weekly diabetes drugs
}

Despite a crowded diabetes market, Intarcia is staking a claim for its injectionfree, once- or twice-yearly ITCA 650. The Boston-based company reported in October that their matchstick-sized ITCA 650 had cleared its first two placebo-controlled phase 3 studies in type 2 diabetes. The system, which primary care physicians insert under a patient's skin in less than five minutes, combines an approved minipump and an existing drug: the active ingredient in the once-weekly glucagonlike peptide-1 (GLP-1) agonist Bydureon (exenatide). If ITCA 650 continues to perform in other ongoing and soon-tobe-initiated trials, it could put both oral and injectable anti-diabetes drugs under pressure.

"I like the idea," says Kristi Silver, an endocrinologist at the University of Maryland in Baltimore. "There is definitely a big market for it, especially in patients who are not compliant," she says. Silver was not involved in developing the drug.

Investors are keen too. They have been willing to back Intarcia's late-stage trials with over $\$ 400$ million. And in November, French pharma Servier, located in Neuilly-

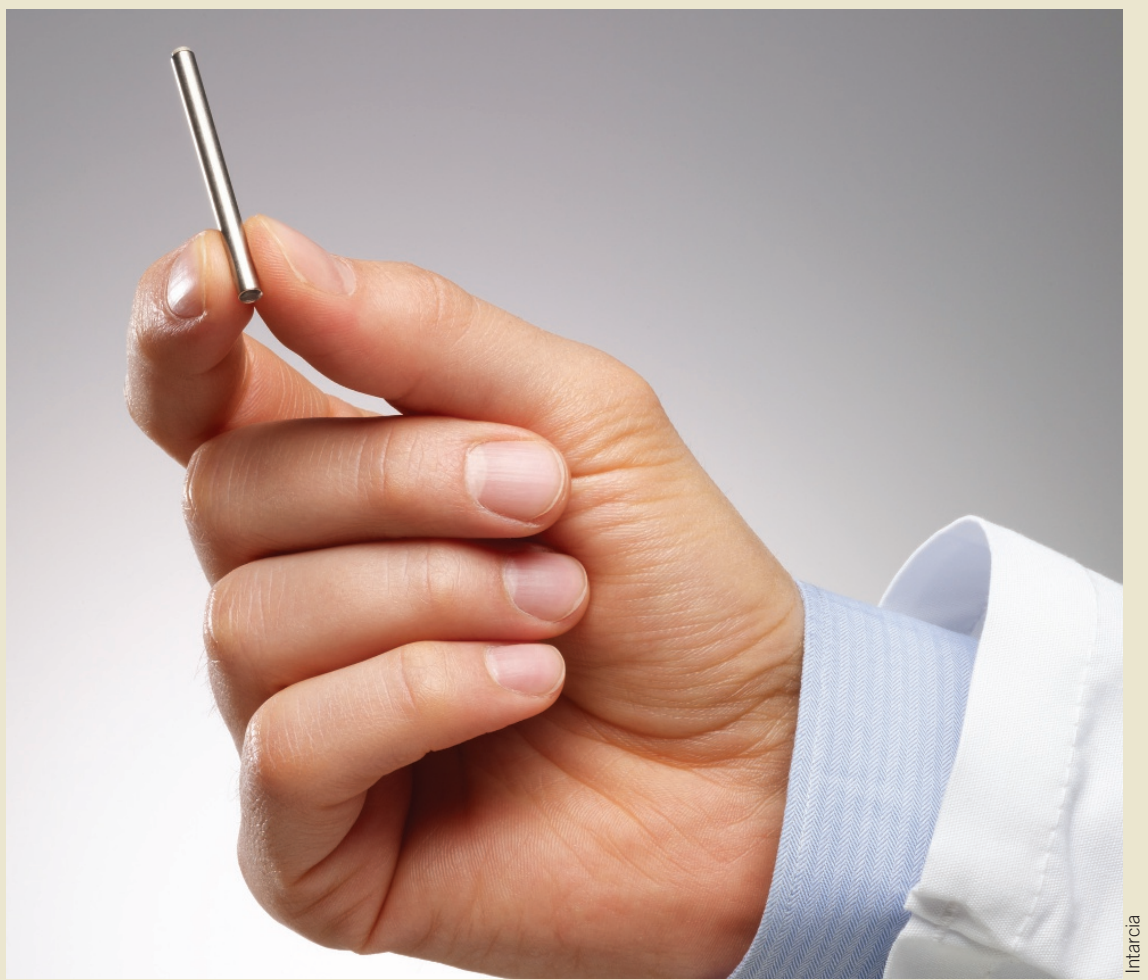

Intarcia's diabetes drug mini-pump attracts a $\$ 1$ billion deal with Servier.
sur-Seine, signed a deal worth over $\$ 1$

billion for rights to develop and sell ITCA 650 outside the US and Japan (the deal consists of $\$ 171$ million upfront and $\$ 880$ million in milestones). The data released so far are encouraging. In the FREEDOM-1 trial, ITCA 650 on top of standard oral diabetes drugs reduced $\mathrm{HbA} 1 \mathrm{c}$ levels by $1.4-1.7 \%$ versus placebo over 39 weeks. In another trial in patients with higher starting $\mathrm{HbAlc}$ levels, the device provided an even greater glycemic effect. "These are stunning and pretty impressive results," says Intarcia CEO Kurt Graves. "There has never been any one drug that caused a sustained $3.4 \%$ reduction in patients-and this is a key part-who were already failing on 2-3 oral medicines." Full data from the two trials are expected to be presented next June at the Annual Diabetes Association meeting in Boston.

The biotech is also running a head-to-head 500-patient trial comparing ITCA 650 with Whitehouse Station, New Jersey-based Merck's Januvia (sitagliptin), a once-daily dipeptidyl peptidase-4 inhibitor. A positive outcome on this could shake up the crowded diabetes market, says Graves. Head-to-head trials between an oral sodium-glucose co-transporter SGLT2 inhibitor, a sulfonylurea and Novo Nordisk's market-leading once-daily GLP-1 agonist Victoza (liraglutide) are also planned for next year.

The potential to do away with injections is a key advantage. "For the vast majority of patients, [injectables] are reserved for after all the orals fail. With our injection-free therapy, we can use it a lot earlier on top of orals," says Graves. Patients, doctors and payers alike are attracted by the prospect of an effective guaranteedcompliance antidiabetic, he adds.

Intarcia expects $50 \%$ of their business to come from the use of ITCA 650 early in disease progression and $50 \%$ from uptake following switches from other GLP-1 agonists ( 5 injectable GLP-1 agonists are already on the market, and several more are in phase 3 trials).

But Eamonn O'Connor, an analyst at Decision Resources in Burlington, Massachusetts, thinks the device will contribute to the overall growth of the GLP-1 market (which is set to expand from $\$ 3$ billion in 2014 to $\$ 9$ billion in 2023) rather than capture market shares from competitors. He forecasts ITCA 650 sales of $\$ 800$ million by 2023 , "slightly less than $10 \%$ of the overall value of the GLP-1 market," he wrote in an e-mail. "We do not anticipate significant shifts in prescribing from oral agents toward ITCA 650," he adds, in part because dipeptidyl peptidase-4-metformin and SGLT2-metformin combination products can already make for a low pill burden. Silver adds that "if [patients] are on something that is working already, I'm not going to change it just because something else is the new and greatest thing on the market."

Although ITCA 650 delivers an approved compound-Londonbased AstraZeneca's exenatide - the innovation is in the new formulation that stabilizes the peptide. This allows Intarcia to sidestep AstraZeneca's patent protection for exenatide. "We have complete freedom to operate," says Graves, adding that the underlying formulation technology also stabilizes other proteins, peptides, antibody fragments and small molecules at body temperature for up to 3.5 years, opening up other drug development options. "We can stabilize and co-deliver two peptides in our mini-pumps, and there has been a lot of work on combining peptides that have synergy and show pretty profound effects on both HbAlc and weight loss."

Asher Mullard Ottawa 